\section{CRUZANDO LA FRONTERA CON ROUSSEAU: EMILIO Y EL VIAJE POR LOS ESTADOS UNIDOS, 1783-1784 DE FRANCISCO DE MIRANDA}

\author{
JOSELYN M. ALMEIDA \\ University of Massachusetts, Amherst \\ almeidab@english.umass.edu
}

Joselyn M. Almeida

Joselyn M. Almeida es Profesora de Literatura Inglesa en la Universidad de Massachusetts, Amherst. Su actividad investigadora se ha enfocado en las relaciones literarias, políticas, y materiales entre Inglaterra, Latinoamérica, España, y África a fines del siglo XVII y a lo largo del XIX. Sus libros y ensayos analizan la obra de escritores británicos que se inspiraron en España y América como William Robertson, Robert Southey, James Montgomery, Charles Darwin, y Richard Robert Madden, y escritores e intelectuales hispanohablantes que se dieron a conocer en Inglaterra como Francisco de Miranda, José Blanco White, Juan Manzano, y W.H. Hudson. Actualmente investiga la relación entre el movimiento abolicionista y la representación histórica de España en Inglaterra.

Publicado originalmente bajo el título «Border Crossing with Rousseau: Emile and Francisco de Miranda's Tour of the United States, 1783-1784, 》 Joselyn M Almeida, Atlantic Studies 9.4 (2012): 387-408. Reproducido y traducido con el permiso de Taylor and Francis (http://www. tandfonline.com).

en la lectura y difusión de Rousseau en España, extendiendo la red de lectores que desafiaron la censura de la Inquisición y crearon una esfera de opinión clandestina. El Diario del viaje por los Estados Unidos de América ilustra cómo Miranda transculturó las teorías de Rousseau sobre el empirismo, el viaje y la educación para desarrollar una epistemología criolla secular que afirmó su visión de la independencia, y aseguró su entrada a la República de Letras de la Ilustración como un sujeto americano. El modelo epistemológico que Miranda deriva del viaje coincide y a la vez diverge de la obra de jesuitas criollos como Francisco Clavijero y otros, quienes, como demuestra Jorge Cañizares-Esguerra, desarrollaron una epistemología patriótica dentro del marco religioso.

Palabras clave: Ilustración, Francisco de Miranda, Jean Jacques Rousseau, Inquisición, España, Estados Unidos, América, Hispanoamérica, Indepencencia, Romanticismo.

\title{
ABSTRACT
}

Drawing on Charles W.J. Withers's analysis of the transnational geographies of Enlightenment culture, this essay reconsiders the early Atlantic border crossings of Francisco de Miranda, forerunner of Latin American independence, in relation to Emile, Jean Jacques Rousseau's revolutionary work on education. During his time as an officer in Cádiz, Spain, Miranda participated in the circulation and reading of Rousseau, extending a network of readers who challenged the Inquisition's criminalization of forbidden books in what might be called a shadow public sphere. Miranda's travel diary of his journey through the United States, Diario del Viaje por los Estados Unidos de América del Norte (The Diary of Francisco de Miranda: Tour of the United States, 17831784) shows how he transculturated Rousseau's theories on empiricism, travel and education, and political maturation to develop a secular creole epistemology that ushered and affirmed his vision of independence, and his entry into the larger Enlightenment republic of letters as a self-identified American. Miranda thus enacted a model of traveling knowledge-making that paralleled and diverged from the work of Jesuits such as Francisco Clavijero and others who, as Jorge CañizaresEsguerra shows, developed patriotic epistemologies within religious frameworks ${ }^{1}$.

Keywords: Enlightenment, Francisco de Miranda, Jean Jacques Rousseau, Inquisition, Spain, United States, America, Latin America, Independence, Romanticism.

Cruzando la frontera con Rousseau: Emilio y el Viaje por los Estados Unidos, 1783-1784 de Francisco de Miranda

JOSELYN M. ALMEIDA 


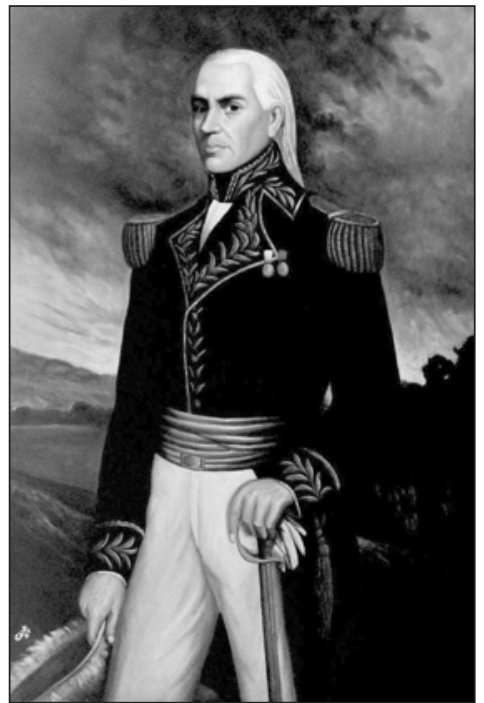

Retrato de Francisco de Miranda. Martín Tovar y Tovar, 1874

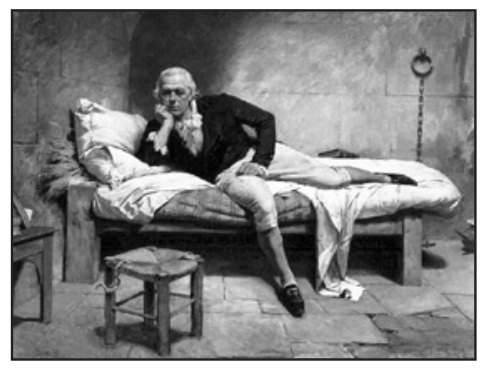

Miranda en la prisión de La Carraca, Arturo Michelena, 1896.

El tomo The Diary of Francisco de Miranda: Tour of the United States, ed. William Spence Robertson (1928) reproduce el manuscrito original de Miranda; he utilizado el título de Robertson para este artículo. Las citas en español provienen de Francisco de Miranda, Colombeia, (1980), vol. 3

3

John Lynch llega a la conclusión de que "[Bolivar's] readiness to write off Miranda and betray him to his enemies was unworthy, no way to treat a precursor of the revolution who at that time had done more to put Spanish America on the map of international awareness than had Bolivar. This was a deep hatred, not a passing resentment, and the anger continued even when he knew the fate of Miranda»
El espíritu de controversia que persiguió a Francisco de Miranda a lo largo de su novelesca vida todavía se hace sentir casi doscientos años después de su muerte. Historiadores como Charles Esdaile resucitan la acusación de aventurero que se lanzó contra Miranda durante su carrera (2008, p. 370). Otros, como Karen Racine (2003) y John Maher (2006), exigen que se le reconozca como uno de los principales protagonistas del mundo revolucionario del Atlántico. Hasta el más breve resumen biográfico muestra la extensión inmensa de sus relaciones. En 1782, sirvió como oficial español en la batalla de Pensacola durante la Guerra de Independencia de Estados Unidos. Cuando se embarcó de Boston a Londres en 1784, después de su viaje por la nueva nación, ya preveía el derrocamiento del imperio español en conversaciones con Alexander Hamilton, Samuel Adams, Henry Knox y William S. Smith ${ }^{2}$. Recorrió Europa y vivió como favorito de Catalina de Rusia antes de dirigirse a Inglaterra y entablar negociaciones con William Pitt para obtener apoyo británico e iniciar la gesta de la independencia durante la crisis de Nootka Sound, en 1790 (Miranda, 1929-50, vol. 15, pp. 106-44). Resueltas las diferencias entre Inglaterra y España sobre las rutas mercantiles en el noroeste del Pacífico, Pitt perdió interés en el asunto, y Miranda pasó a Francia. Allí fue general de la República Francesa hasta que fue apresado por los jacobinos, quienes continuarían hostigándole con arrestos aun después de su exoneración. En 1798 regresó a Inglaterra, reanudó las negociaciones con Pitt y organizó una expedición armada a Venezuela, que emprendió en 1806. A pesar del espectacular fracaso de la iniciativa, Miranda volvió a Londres y retomó la causa de la independencia hispanoamericana, logrando el apoyo entusiasta de la intelligentsia. Cuando Simón Bolívar llegó a Inglaterra en 1810 con la delegación venezolana que incluía a Andrés Bello, fue Miranda quien les gestionó una audiencia con el Marqués de Wellesley (Lynch, 2006, pp. 50-53).

(«La disposición de Bolívar para descartar a Miranda y entregarle a sus enemigos fue indigna, y no la forma de tratar a un precursor de la revo- ución que en aquel momento pañola en el mapa internacional. Fue un odio profundo, no había hecho más que Bolivar
No sorprende por lo tanto que, a la muerte de Miranda de tifus en un calabozo de $\mathrm{La} \mathrm{Ca}-$ rraca (Cádiz) en 1816, The Quarterly Review elogiara al hombre que el pueblo británico conocía como «el General Miranda» desde la década de 1790, cuando había luchado contra ellos en el ejército francés:

[W] cannot omit to notice the recent death of General Miranda, the author and the leader of the first attempt to obtain [South America's] political freedom ... His sincerity in the cause which he had undertaken cannot be questioned, for the last exertion he made for its success, and which terminated in his own captivity and death, was made against the advice of his more prudent friends (Wellesley and Jacob, 1817, p. 553).

No podemos pasar por alto la muerte reciente del general Miranda, autor y líder del primer intento de obtener la libertad política de América del Sur ... no se puede dudar de su sinceridad por la causa a que se dedicó, pues el último esfuerzo que hizo para que tuviera éxito, y que le costó la libertad y la vida, fue contra el consejo de sus amigos más prudentes.

Sarah Andrews, su compañera, y sus hijos Leandro y Francisco, viejos amigos como Jeremy Bentham y John Turnbull, y figuras como Richard Wellesley en Inglaterra y James Madison en Estados Unidos guardaron luto privado por su muerte (Robertson, 1969, vol. 2, pp. 225-228; Racine, 2003, p. 253). Circulaba en aquel momento la historia del arresto de Miranda en Puerto Cabello después de que Bolívar supervisara su captura y lo entregara a Domingo Monteverde en 18123. Desde Londres, José Blanco White comentó en el El Español: «Miranda se ve abandonado de todo el mundo, sin que haya ni uno que lo liberte [sic] de las manos de los españoles» (Blanco White, 1812, p. 423) ${ }^{4}$. La desgracia de Miranda aseguró que Bolívar recibiera la admiración de la segunda generación de románticos ingleses como Lord Byron, quien puso el nombre de Bolívar a su barco y en algún momento pensó en dirigirse hacia América del Sur, y escritores de menor estatura como James Scott Walker, quien en el poema The South American: a un resentimento pasajero, y el furor continuó aún después de enterarse del destino que había corrido Miranda») (Lynch, 2006, p. 281).
Veáse Pons, Blanco White $y$ América (2006) para un tratamiento a fondo sobre el pape de El Español en Latinoamérica. 
Metrical Tale (1816) intentó la que quizás fuera primera composición con rasgos épicos sobre el libertador 5 .

El conspicuo silencio de los amigos de Miranda después de su captura y muerte, y el hecho de que su archivo de 63 tomos, titulado Colombeia, no se descubriera hasta 1922, fueron parcialmente responsables de que «precursor» se consagrara como el epíteto por excelencia para referirse a su persona ${ }^{6}$. Este título halagador oscurece, sin embargo, la gran importancia del archivo mirandino para la historia literaria y política de la época de transición entre la Ilustración y el Romanticismo en el Atlántico?. El tomo inicial del archivo, The Diary of Francisco Miranda: Tour of the United States, editado en 1928, pone en primer plano la contemporaneidad de Miranda con el ámbito revolucionario de Norteamérica y Europa. Los historiadores han interpretado el viaje de Miranda como un episodio de la influencia de la tradición angloamericana en la constitución venezolana o lo comparan con La democracia en América de Alexis de Tocqueville (Bushnell en Maher 2006, pp. 19-21), interpretaciones que consideran a Miranda como un agente político dentro del marco de la historia nacional, bien sea de Venezuela o de Estados Unidos. La teorización de la transnacionalidad en los campos de la historiografía y la crítica literaria invitan a reconsiderar este texto, central para la cultura del arco atlántico. El presente estudio aplica el trabajo de Charles Withers (2007) sobre las redes y espacios geográficos de la cultura de la Ilustración y el análisis de la epistemología criolla de Jorge CañizaresEsguerra (2006) para examinar cómo Miranda, al cruzar el Atlántico, transforma la pedagogía de Jean-Jacques Rousseau en Emilio al elaborar en su diario de viaje la epistemología experimental del sujeto criollo como expresión de independencia política. Si en el texto de Rousseau el viaje continental o grand tour funciona para consolidar la madurez cívica de Emilio con relación a una idea continental de Europa, en el Viaje por Estados Unidos tanto el viajar como la escritura llevan a Miranda a elaborar una idea continental de América. Esta idea establece un espacio para cuestionar las categorías de nacionalidad y ciudadanía, precipitando su abandono de España. El periplo de Miranda con Rousseau por las fronteras de España y Estados Unidos contri- buye a reconceptualizar la Ilustración como un movimento transnacional, pluricéntrico y migratorio que se desplaza a través del viaje.

\section{Miranda y Rousseau en España}

A lo largo del siglo $\mathrm{XX}$, expertos en Miranda como William Spence Robertson (1969), Lautico García (1961) y otros han observado la influencia de Rousseau en el desarrollo de su pensamiento. J. R. Spell resume la opinión general: «Of the many who came into touch with the ideas of Rousseau, the most effective disseminator was probably Francisco Miranda, the herald of SpanishAmerican independence» («De los muchos que estuvieron en contacto con las ideas de Rousseau, Francisco Miranda, heraldo de la independencia hispanoamericana, fue tal vez su divulgador más eficaz») (Spell, 1928, p. 131) $)^{8}$ García subraya la influencia del Emilio, añadiendo que «Miranda aplica fielmente estas fórmulas roussonianas del viaje ilustrado» con relación a los viajes europeos de Miranda (García, 1961, p. 307). La historia de la recepción del trabajo de Rousseau en España, sin embargo, sugiere que Emilio influyó en Miranda durante los años 1780-1784, que culminaron en su compromiso con la gesta de la independencia. Dicha historia vislumbra los contornos de la Ilustración en el mundo hispano, el cual, según Withers, hay que reconceptualizar como una red de sistemas y prácticas interrelacionados en vez del marco tradicional de centros y periferias:

The Enlightenment as [...] Republic of Letters, as transnational cosmopolitanism 'above' national context-was an actual space defined by its practices, languages, and networks, by what people did in particular places, by how Enlightenment ideas about reason, criticism, and tolerance were lived and worked with (Withers, 2007, p. 72).

La Ilustración como [...] una república de las letras, como un cosmopolitismo transnacional 'por encima' del contexto nacional-fue un espacio real definido por sus prácticas, idiomas, y redes, por lo que hacían las personas en lugares específicos, y por el modo en que se vivía con las ideas ilustradas sobre la razón, la crítica y la tolerancia.

En España, los libreros que suministraban obras prohibidas a los lectores que los frecuentaban formaron uno de estos sistemas en



Lord Byron. Richard Westall

5

Sobre Byron y Sur América, véase Heinowitz (2010, pp. 158 182); sobre James Scott Walker, Almeida (2013, pp. 101-122).

6

Miranda no desapareció por completo del archivo británico. Todavía en 1858, Harriet Martineau lo recordaba como «the great champion of independence» (el gran campeón de la independencia). Véase Martineau (1858, p. 50).

En la década de 1810 Miranda confió en redes mercantiles, políticas y diplomáticas británicas para garantizar la supervivencia de los tomos. Antes de ser arrestado los había enviado a Curazao en tres baúles sellados a la atención de una empresa. Cuando llegaron, el gobernador los confiscó y pidió instrucciones para su disposición a Lord Henry Bathurst, entonces Secretario de Guerra y las Colonias. Bathurst ordenó que enviara los tomos a Londres, donde guardó el archivo bajo el sello del Foreign Office hasta su jubilación en 1827, cuando lo trasladó a su biblioteca privada. William Spence Robertson, el eminente estudioso mirandino de la Universidad de Illinois, investigó su paradero y organizó su venta al gobierno venezolano. Veáse William Spence Robertson, Introduction to The Diary of Francisco Miranda, (Miranda, 1929, pp. XIX-XXV). El Archivo del General Miranda se publicó de 1939 a 1952, y reproduce la organización y la ortografía de Miranda. La edición venezolana más reciente del archivo, comenzada en 1977 utiliza el título original de Miranda, Colombeia, y traduce todos los documentos al español.

8

Salvo indicación en sentido contrario, las traducciones del inglés son de la autora.

Cruzando la frontera con Rousseau: Emilio y el Viaje por los Estados Unidos, 1783-1784 de Francisco de Miranda

JOSELYN M. ALMEIDA 


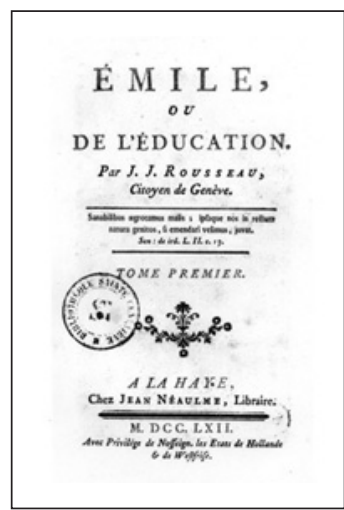

9

Véase a Herr (1969, pp. 154163) para un panorama de cómo las sociedades económicas transmitieron la llustración; un tratamiento más reciente que aborda la cultura de la prensa y las bibliotecas puede hallarse en Joaquín Álvarez Barrientos, François Lopez, e Inmaculada Urzainqui, La república de las letras en la España del Siglo XVIII (1995).

10

En su estudio clásico sobre la lnquisición, Marcelin Deforneaux identifica cinco tipos de obras en el índice: «1. Obras contrarias a la fe católica romana [...] 2) Obras de nigromancia, astrología o que fomentan la superstición [...] 3) Las obras 'que tratan cuentan y enseñan cosas de proposito lascivas, de amores y otras cualesquira como dañosas a las buenas costumbres de la Iglesia cristiana' [...] 4) Las obras publicadas sin nombre del autor ... 5) Las obras que atentan contra la buena reputación del próiimo.» Se clasificaba a autores como «damnatae memoriae» prohibidos para siempre, condenados, o anónimos. Rousseau y la mayoría de los philosophes pertenecián a la primera clasificación. Veáse Deforneaux, La Inquisición y censura de libros en la España del siglo XVIII, (1973, pp. 50-51); además Francisco Bethencourt, The Inquisition: a Global History 1478-1834, trans. Jean Birrell (2009).

11

Agradezco el tiempo y la ayuda que me brindaron los bibliotecarios del Archivo Histórico Nacional, Ignacio Panizo Santos, Director de la sección de Inquisición, Emilio José Sanz Hernández, y Rocío de la Nogal Fernández.

Cruzando la frontera con Rousseau: Emilio y el Viaje por los Estados Unidos, 1783-1784 de Francisco de Miranda

JOSELYN M. ALMEIDA medio de corrientes opuestas: por un lado, la censura de la Inquisición, y por el contrario, las reformas institucionales de las universidades y las fuerzas armadas que tenían el respaldo de la corona. Miranda adquiere a Rousseau en el espacio institucional del ejército y el social de la tertulia, unos ambientes donde hablar sobre obras prohibidas nutría el pensamiento frente a la amenaza de los procesos inquisitoriales y la cárcel ${ }^{9}$.

Aunque las reformas de Carlos III habían debilitado el poder de la Inquisición a lo largo del siglo XVIII, todavía tenía garras, como mostró el proceso del sabio peruano Pablo de Olavide en 1776, un acto que privó a España y América de uno de sus líderes más ilustres (Pérez, 2005, pp. 212-213; Deforneaux, 1973, pp. 341-364). Los índices de obras prohibidas reflejaban la doctrina de la jerarquía inquisitorial, que controlaba el acceso de los lectores a dichos textos ${ }^{10}$. En los escalones más altos de ésta, los inquisidores enjuiciaban y sentenciaban, censuraban $u$ otorgaban licencias para obras prohibidas a lectores selectos bajo la condición de que no las compartieran con aquellos sin autorización (Perojo, 2010, pp. 191-212). Los muelles de los puertos de mar se convirtieron en puntos de control para los revisores, quienes se aseguraban de que los cargamentos de libros correspondían a los inventarios de antemano aprobados por el tribunal. En caso de hallar una obra prohibida, los revisores confiscaban los tomos e iniciaban un proceso contra el librero. Entre los cientos de autores prohibidos, Rousseau destaca por tener dos entradas en el índice del siglo XVIII, en 1756 y en 1764 respectivamente ${ }^{11}$. Los inquisidores señalan a Emilio específicamente en la segunda entrada y su censura absoluta se corresponde con otras reacciones extremas en Europa contra la misma. Cuando Emilio aparece en Francia en 1762, se publica una orden de arresto contra Rousseau, y Emilio se censura, confisca y quema públicamente en una hoguera. Al cabo de unos meses vuelve a quemarse en público, junto a El contrato social, en Ginebra; en España sucede lo mismo en 1765 (Rosenblatt, 2007, p. 63). Hasta en Inglaterra, donde autores como David Hume, William Goodwin y Mary Wollstonecraft recibieron Emilio con entusiasmo, se criticó el innegable desafío de Rousseau contra la religión institucionalizada (Warner, 1944, pp. 786-787).
Según Rousseau, su protagonista, «el hombre de la naturaleza», debía educarse para «elegir la [religión] a la que le conduzca el mejor uso de la razón» (1971, p. 371), convirtiendo así la fe religiosa en un asunto profundamente individual. Esta convicción sienta las bases para la profesión del vicario saboyano, quien define la fe como nacida de la experiencia propia y que se manifiesta a través de un espíritu de escepticismo reverente. Dichas ideas bastaban para que la Inquisición censurara a Rousseau, mas el tribunal fue más alla de la fórmula de "proposiciones temerarias, erroneas, heréticas» que se usaron contra otros escritores como Diderot y el popular Voltaire. La desobediencia religiosa que la lectura de Emilio podía engendrar se vinculó con las consecuencias políticas de la epistemología rousseauniana:

Recelamos que del mismo Autor se hayan introducido tal vez, o se introduzcan en adelante algunas otras obras, desde ahora las declaramos todas prohibidas como de Autor hereje [...] y siempre erroneas, opuestas a la religión, a las buenas costumbres, y al gobierno civil, y justa obediencia debida a los legitimos soberanos, y superiores; declarando que esta prohibición se extiende a todos aquellos que tuviesen licencia de leer libros prohibidos (AHN, 2012, Inquisición, Libro, 1319).

Los inquisidores comprendieron que, como proyecto pedagógico, el Emilio de Rousseau incitaba a sus lectores a examinar y cuestionar todas las jerarquías, no sólo las eclesiásticas. «Los hombres no son, por naturaleza, ni reyes, ni potentados, ni cortesanos, ni ricos», escribe. "Todos nacieron desnudos y pobres, sujetos todos a las miserias de la vi$\mathrm{da}$, a los pesares, a los males, a las necesidades, a toda clase de dolores; en fin, condenados a muerte» (Rousseau, 1979, p. 319). Estas ideas niveladoras, que resucitaban las doctrinas de los levellers ingleses, no eran aptas ni siquiera para lectores con licencia.

No obstante, la popularidad de Rousseau creció entre aquellos lectores que desafiaron la censura inquisitorial en España y América. Los inquisidores mencionan traducciones de Emilio y el Contrato Social que circulaban ya en 1764, «que han traducido y leen en estos reynos» (AHN, 2012, Inquisición, Libro 1319). En Madrid aparecieron en 1762 reseñas sobre ambos libros, y en Galicia las autori- 
dades eclesiásticas llegaron a culpar a Emilio de las costumbres alteradas de la juventud (Domínguez Ortiz, 2005, pp. 316-317). Como demuestra Germán Ramírez Aledón, «la prohibición llegó tarde, pues las ideas de Rousseau se habían extendido entre las clases ilustradas de España y América» (Ramírez Aledón, 2012, p. 213). Además, la tarea de vigilar el contrabando de obras prohibidas se hacía más difícil por el esfuerzo conjunto de los libreros; en Cádiz, por ejemplo, Antonio Canis, Julián Mutis, Du Bertrand, Caila, Solier y Cabanes se enfrentaron al tribunal más de una vez. Un comisionado aconsejaba en 1780 que para iniciar un proceso se aceptara la denuncia de una sola persona "para proceder en las diligencias, según lo mandado [...] que siendo tantos, $\mathrm{y}$ tan graves los asuntos que ocurrían en la comisión se paraba en el reconocimiento de libros prohibidos, y pinturas obscenas [...] pues de otra manera serían innumerables estos expedientes» (AHN, 2012, Inquisición 3721.189). Se incoaron procesos contra extranjeros como Don Josef Gannier, músico que trabajaba para el Teatro Francés y que fue encarcelado por leer a Rousseau y prestar sus libros (AHN, 2012, Inquisición, libro 3721.133). También padecieron procesos judiciales criollos como Joaquín Morales, de Santiago de Cuba, o incluso Juan Manuel Abad y Queipó, obispo de Michoacán, (AHN, 2012, Inquisición, libro 3721.132).

El caso que tocó a Miranda de cerca fue el proceso contra Don Manuel Villalta, nieto del Marqués de Casa Concha y criollo nacido en Perú, quien ejercía el rango de teniente coronel en el regimiento de Miranda. En 1776 se acusó a Villalta de tener libros prohibidos y grabados «obscenos», así como de defender opiniones heréticas que, según ciertos testigos, comentaba con Miranda (AHN, 2012, Inquisición, libro 3721.166). El caso de Villalta es ilustrativo de las conversaciones que él y otros oficiales jóvenes mantenían sobre los autores leídos en Cádiz por aquel entonces, y supone una constatación de la época en que Miranda ingresa en los libros de la Inquisición. Villalta daba el ejemplo de un joven destacado que completaba su educación a través del viaje; por encargo de Carlos III había acompañado al Marqués de Ovando en Francia e Inglaterra. Desde el punto de vista de la Inquisición, el viaje de Villalta estaba relacionado a su lectura de autores prohibidos, su profesión de ideas polémicas, y la acusación de liberti- naje que es recurrente en el sumario. Varios testigos afirmaron que Villalta había visitado a Voltaire, y uno señaló que «había visto su librería, y particularidad de su gabinete; con cuyas noticias fue verificando la que le habían dado del libertinaje de este reo, y no le volvió a tratar más» (AHN, 2012, Inquisición, libro 3721.166). Otros atestiguaron que le habían sorprendido in flagrante delicto leyendo a Rousseau y la historia del Abbé Raynal. Las ideas imputadas a Villalta, si bien desfiguradas por testimonios de segunda y tercera mano, reflejan sus lecturas de Voltaire y Rousseau. Villalta negó la existencia del infierno y se mofaba de las imágenes del diablo, afirmando que «eso era únicamente para amonestar a la gente $[\ldots]$ no había infierno porque quién le había visto y asimismo los Diablos que se pintan con rabo y cuernos, esas pinturas eran una bobería» (AHN, 2012, Inquisición, libro 3721.166). Como si eso fuera poco, en una de las conversaciones que se le oyó mantener con Miranda y el marqués de Ovando se preguntaba si el poder de la Inquisición le venía por derecho natural o ley, y si era beneficioso o perjudicial para las letras. Según el testigo, todos coincidieron sobre este último punto.

Villalta y los otros jóvenes que emulaban las tertulias de Pablo de Olavide y Jovellanos formaron un entramado de contactos a través del cual Miranda adquirió y estudió obras prohibidas como las de Rousseau y Voltaire en la década de 1770. Aunque la recepción de Rousseau y otros autores en España no se da en espacios públicos como tabernas y cafés, donde sí se manifiesta la Ilustración en Francia e Inglaterra, el entorno de Miranda en Cádiz indica la presencia de un sistema clandestino de lectores y libreros que engendró una esfera «umbría» para la difusión e intercambio de ideas. García relata cómo la Inquisición de Sevilla comienza a investigar a Miranda en 1778, y seguidamente de 1781 a 1783 (García, 1961, pp. 379-392). Los sumarios no han aparecido, mas el Santo Oficio perseguía a Miranda por los mismos «delitos de proposiciones [heréticas] y retención de libros prohibidos» (AHN, 2012, Inquisición, libro 2190.4). De todos los libros de Miranda, el de Rousseau encabezaba la lista de los prohibidos. Otros como Voltaire y el Robinson Crusoe de Daniel Defoe (la novela cuya lectura Rousseau autoriza a su alumno) hubiesen aumentado las pruebas en contra suya ${ }^{12}$. Todo ello
12

García observa que Miranda no sentía el mismo entusiasmo por Voltaire que tenía por otros au tores franceses. Veáse Francisco de Miranda (1961, p. 329).
Cruzando la frontera con Rousseau: Emilio y el Viaje por los Estados Unidos, 1783-1784 de Francisco de Miranda

JOSELYN M. ALMEIDA 




José de Gálvez

13

El original dice «L'homme vraiment libre ne veut que ce qu'il peut, et fait ce qu'il lui plaît [y hace lo que quiere].» Rousseau, Emile, ou, D'léducation (2013, p. 309)

Cruzando la frontera con Rousseau: Emilio y el Viaje por los Estados Unidos, 1783-1784 de Francisco de Miranda

JOSELYN M. ALMEIDA trajo como resultado una orden de arresto que coincidió con los otros problemas de Miranda en el ejército. Juan Roca, antiguo amigo de Miranda, le acusó de abusar de sus subalternos y malgastar los fondos del regimiento, ordenando su arresto en 1779 (Miranda, 1978, vol. 1, pp. 556-582). Al cabo de dos años, José de Gálvez, ministro de Indias, acusó a Miranda de ser un agente inglés y suministrar planes de ataque a John Campbell, el general británico en la batalla de Pensacola. Miranda fue detenido en $\mathrm{Cu}-$ ba, donde servía como ayudante de campo a Juan Manuel de Cagigal, amigo y protector suyo, quien logró que su arresto fuera por poco tiempo (Hernández, 2006, pp. 54-97; Racine, 2003, pp. 26-27; Robertson, 1969, vol. 1, pp. 22-29). La facción de Gálvez consiguió otra orden poco después. El contraste entre las respectivas suertes de Miranda y de Villalta no podía ser mayor. Los contactos de Villalta le ayudaron a superar el proceso inquisitorial y regresó a Perú como corregidor de Abacay, donde estuvo al mando de una división dirigida contra las fuerzas de Túpac Amaru. Para evitar una persecución política (y sin saberlo, un proceso inquisitorial), Miranda se embarcó de La Habana a Charleston en abril de 1783, en un peregrinaje que plasmaría la interrelación entre las ideas roussonianas de la educación, libertad individual y madurez política.

«No consultemos otro libro que el del mundo»: epistemología, viaje, revolución

La salida apresurada de Cuba y el período de incertidumbre y peligro que Miranda enfrentaba lo llevaron a reflexionar sobre su vida. Aunque no cita una fuente específica, Miranda claramente se inspira en los temas narrativos de Emilio y el proyecto epistemológico de Rousseau en la carta que le escribe a Cagigal el 16 de abril de 1783, poco antes de su partida a Estados Unidos. Este préstamo temático le permitió explicarse y elaborar un cuadro autobiográfico que contraargumentaba la versión oficial de su vida, i.e., que era un fugitivo de la corona. Miranda escribe:

En dirigirme a los Estados Unidos de América, no solo fue por sustraerme a la tropelía que conmigo se intentó, sino para dar al mismo tiempo principio a mis viajes en países extranjeros, que sabe $V$. fue siempre mi intención concluída la Guerra; con este propio designio he cultivado los principales idiomas de Europa, que fueron la profesión en que desde mis tiernos años, me colocó la suerte y mi nacimiento. Todos estos principios (que aún no son otra cosa), toda esta simiente que con no pequeño afán y gastos se ha estado sembrando en mi entendimiento por espacio de treinta años que tengo de edad, quedaría desde luego sin fruto ni provecho, por falta de cultura a tiempo. La experiencia y conocimiento que el hombre adquiere, visitando y examinando personalmente con inteligencia prolija el gran libro del universo; las sociedades más sabias y virtuosas que lo componen; sus leyes, gobierno, agricultura, policía, comercio, arte militar, navegación, ciencias, artes, etc. es lo que únicamente puede sazonar el fruto y completar en algún modo la obra magna de formar un hombre sólido y de provecho (Miranda, 1978, vol. 2, p. 423).

Un breve análisis intertextual de estos temas muestra como presagian la potencialidad revolucionaria del viaje americano de Miranda. El primero, el razonamiento de Miranda a Cagigal sobre su propósito, «la obra magna de formar un hombre sólido y de provecho", recoge el lenguaje de Rousseau cuando éste formula su proyecto pedagógico al principio de Emilio. Rousseau propone «un hombre educado únicamente para él» según «la educación [...] de la naturaleza» para contrarrestar la pedagogía que hace «dobles a los hombres, que con la apariencia de proporcionar beneficios a los demás, jamás hacen nada que no sea en provecho propio» (1971, p. 70). El hombre natural, señala, no será educado para «el orden social, donde todas las plazas están señaladas» mas seguirá el camino de «la naturaleza [que] le llama a vivir la vida humana» (1971, p. 71) y por lo tanto, podrá defenderse contra los accidentes de la fortuna al igual que el «hombre sólido» de Miranda. Rousseau recalca la oposición entre la naturaleza y la sociedad a través de Emilio, y concluye que sólo la naturaleza garantiza al hombre la libertad como autosuficiencia, la virtud que Emerson llamaría self-reliance un siglo después. Escribe Rousseau, «El hombre verdaderamente libre solamente quiere lo que puede y hace lo que le conviene [quiere]. Esa es mi máxima fundamental» $\left(1971\right.$, p. 129) ${ }^{13}$. La consecución de esta forma de ser es vital para Rousseau frente a «el espíritu inquieto y revoltoso de este siglo» (1971, p. 72). Añade:

Confiáis en el orden actual de la sociedad y no reflexionáis que está sujeto a inevitables revoluciones, y no habéis previsto ni prevenido lo que puede tocarle 
a vuestros hijos. El pequeño se convierte en grande o viceversa, pobre el rico, vasallo el monarca. ¿Son tan raros los golpes de la fortuna que podáis creeros exentos de ellos? Nos vamos acercando al estado de crisis y al siglo de las revoluciones. ¿Quién puede responderos de lo que seréis entonces? Todo cuanto han realizado los hombres, los hombres lo pueden destruir. No existen otros caracteres indelebles que los que estampa la naturaleza, la cual no hace príncipes, ni ricos [...] Considero imposible que las monarquías de Europa duraren mucho tiempo. (Rousseau, 1971, p. 283; mi énfasis).

Rousseau esclarece la idea de la igualdad de los hombres en el estado natural y muestra que el orden social que la infrije es insostenible, vaticinado así los desafíos a la monarquía y al imperio que se desencadenaron en el arco atlántico de 1776 a 1824. El protagonista de Rousseau es por lo tanto un hombre nuevo para una época nueva. Al hacer un gesto tácito hacia Emilio en su carta, Miranda también invoca la visión del filósofo ginebrino de un orden social mutable.

El segundo tema roussoniano en la carta de Miranda es «La experiencia y conocimiento que el hombre adquiere, visitando y examinando personalmente con inteligencia prolija el gran libro del universo». La idea recapitula la importancia del empirismo pedagógico que Rousseau expone en el tercer libro de Emilio: «En las primeras operaciones del espíritu los sentidos deben ser siempre sus guías. Ningún otro libro que no sea el mundo [...] Poned a su alcance las cuestiones y dejad que él las resuelva. Que no sepa nada porque se las habéis propuesto, sino porque las haya comprendido el mismo» (Rousseau, 1971, p. 47). Este método pedagógico fortalece la capacidad para la evaluación y el juicio independiente del alumno, competencias del sujeto adulto en su libertad. Al insistir en el empirismo, Rousseau se opone al uso de la educación para reproducir las jerarquías sociales. Ausente la capacidad de un sujeto de formar juicios independientes por medio de la razón, la opinión sustituye al pensamiento, y así priva al individuo de su libertad. Declara que la iglesia es el mayor portavoz de la opinión, y subraya que «Donde principalmente se muestra más tiránica la opinión es en lo que hace referencia a la cuestión religiosa» (Rousseau, 1971, p. 370). El antídoto es educar a un alumno que «hace uso de su razón, y no de la ajena» (1971, p. 300). Rousseau interrelaciona la capacidad de raciocinio y el juicio del individuo a la actualización de la igualdad del hombre independientemente de su posición social, ya que «a los ojos de un pensador desaparecen todas las distinciones civiles» (1971, p. 324). El empirismo enfocado de esta manera afirma el potencial humano de imaginar una rectificación verdadera a la «igualdad de derecho vana y quimérica» que Rousseau señala en el orden cívico (1971, p. 338), y establece un método disidente y a la vez secular para interpretar el orden social y político.

El último tema roussoniano que Miranda trata es el viajar con propósito para examinar personalmente «las sociedades más sabias y virtuosas que lo componen; sus leyes, gobierno, agricultura, policía, comercio, arte militar, navegación, ciencias, artes, etc.». Miranda había escrito diarios de sus viajes por España, y había tomado notas de observación del libro de John Marshall, Travels Through France and Spain (1776). El papel de viajero como reportero desinteresado no era, sin embargo, el fin de la última etapa la educación de un individuo de juicio independiente. Rousseau critica ese modo de viaje y el grand tour, que para los 1760 se había popularizado hasta llegar a los estereotipos. El filósofo ridiculiza a aquellos viajeros que «mientras que un francés frecuenta a los artistas de un país, un inglés hace dibujar alguna antigüedad y un alemán lleva su álbum a casa de los sabios» (1971, p. 621). El viajar con propósito, según explica en el quinto libro, es «que primero estudie la naturaleza del Gobierno en general, sus diversas formas, y, por ultimo, el Gobierno particular en que cada uno ha nacido, para saber si le conviene vivir en él» (Rousseau, 1971, p. 624). Una persona debe elegir en plena consciencia si participará en el contrato social o no porque «el hombre y el ciudadano, quienquiera que sea, no tiene otro caudal que dar a la sociedad que a sí propio» (1971, p. 283). Rousseau enfatiza la ciencia del derecho político como objeto de estudio para el viajero, e instruye a «el que pretenda formarse un juicio verdadero de los gobiernos» (1971, p. 628) a examinar cómo sociedades particulares implementan el contrato social para reconciliar al hombre en el estado de la naturaleza con la nación como expresión de la soberanía popular. "Como los particulares se han sometido al soberano, y como la autoridad soberana no es otra cosa que la voluntad general, veremos de qué modo obedeciendo cada hombre al soberano, solo se obedece a si mismo, y cómo es más libre en el pacto social que en el estado de la naturaleza» (Rousseau,

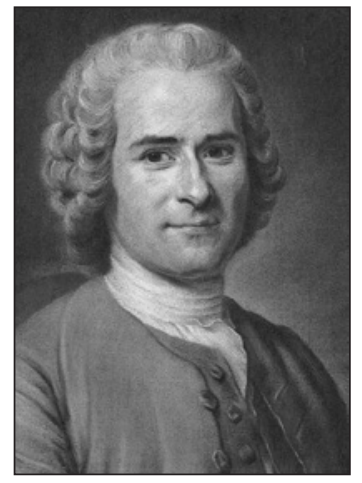

Jean-Jacques Rousseau. Maurice Quentin de La Tour, 1753

Cruzando la frontera con Rousseau: Emilio y el Viaje por los Estados Unidos, 1783-1784 de Francisco de Miranda

JOSELYN M. ALMEIDA 




14

Compárese con el original: "que m'importe? Et, qu'y puisje faire?» [¿Qué puedo hacer al respecto?]. Rousseau, Emile, ou, D'léducation (2013, p. 837).

15

Adams le explicó a James Lloyd porqué Estados Unidos no participó en la independencia de Latinoamérica: «Had Mr. Pitt thought of the consequences of opening a navigable canal across the isthmus to the South Sea? Who was to have jurisdiction and dominion of that canal? What would be the effect of an independent, free government in South America? Could common sense in South America not think of a navy? [...] Where is this thoughtless boy leading his king and country? I am apprehensive you will think me as mad now as I then thought Pitt and Miranda [...] Should I have any thing to do in the business? No! If both houses of Congress, and Washington and Hamilton should all agree in an address to me, advising me to engage in such a Quixotic attack of a windmill I would have never put my hand to it» ( Había penado el señor Pitt en las consecuencias de abrir un canal navegable por el istmo hasta el Pacífico? ¿Quién tendría jurisdicción y dominio de ese canale ¿Cuál sería el efecto de un gobierno independiente, libre en

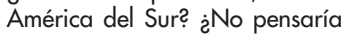
el sentido común de América del Sur en una marina? ... ¿Adónde llevaba este muchacho imprudente a su rey y a su país? Soy aprensivo y usted me pensará tan loco ahora como en aquel entonces pensé a Pitt y a Miranda $[. ..] \dot{\partial}^{T}$ Tendría algo que ver en el asunto? ¡No! Si ambas cámaras del Congreso, Washington y
1971, pp. 632-633). La meta final del estudio de distintos gobiernos es que el alumno investigue el gobierno de su país y se pregunte «¿Qué me importa? ¿Qué tengo yo que ver con esto?» ${ }^{14}$. El individuo se conciencia de su poder de elección y potencia para actuar, y de su derecho de consentir o negarse a participar en el contrato social mediante el análisis de la legitimidad política del estado como derivada de la soberanía popular.

Cagigal se percató de los matices roussonianos en la carta de su ayudante de campo, y en su respuesta, resaltó el valor que Miranda tenía como súbdito español: «Yo por obligación y justicia, debo manifestar al Rey el distinguido mérito de sus servicios de Vmd. como testigo que soy de ellos y asimismo las ventajas que al Estado puedan resultar de sus conocimientos y constante aplicación» (Cagigal en Miranda, 1978, vol. 2, p. 449). Miranda al servicio de la corona era mucho más valioso para España que el hombre que la carta auguraba. No obstante, Cagigal apoyó el viaje de Miranda y le dio varias cartas de presentación, incluyendo una para George Washington (Miranda, 1978, vol. 3, p. 85). Le confesó sus inquietudes a Francisco Rendón, el cónsul español en Filadelfia, pidiéndole que tratara a Miranda bien, «no vaya a segregarse del estado» (Cagigal, en Miranda, 1978, vol. 3, p. 86). Los riesgos considerables que Cagigal tomó por Miranda muestran que nunca dudó de su lealtad, pero en la advertencia a Rendón, dejó entrever la ansiedad que despertó el eco del «el espíritu inquieto y revoltoso de este siglo» que repercutía a la distancia en las palabras de su protegido.

\section{De libros y batallas: el viaje y la seculariza- ción de la epistemología patriótica}

Los núcleos y redes bibliófilas en los espacios institucionales y sociales de la Ilustración que facilitaron la lectura de Miranda de Rousseau y otros autores proscritos en España y América se multiplicaron una vez cruzó a la costa este de Estados Unidos. Las cartas de Cagigal y las introducciones que James Seagrove le hizo en Carolina del Norte le proporcionaron un comienzo auspicioso, mas no explican la constelación de los contactos que hizo Miranda, y los conocimientos cívicos y políticos que obtuvo a través de ellos. Recuerda el presidente John Adams:

During our revolutionary war, General Miranda came to the United States, traveled through many, if not all of them, was introduced to General Washington and his aids, secretaries, [...] to the other general officer and their families [...] He acquired the character of a classical scholar, of a man of universal knowledge, of a great general, and master of all the military sciences [...] It was a general opinion and report, that he knew more of the families, parties, and connections in the United States, than any other man in them; that he knew more of every campaign, siege, battle, and skirmish that had ever occurred in the whole war, than any officer of our army, or any statesman in our councils (Adams, 2010, vol. 10, p. 134).

Durante nuestra revolución, el General Miranda vino a Estados Unidos, viajó por muchos, si no todos ellos, fue presentado al general Washington y a sus ayudantes y secretarios [...] a los otros oficiales y sus familias [...] Adquirió la reputación de un estudioso de los clásicos, de un hombre de conocimientos universales, de un gran general, y maestro de todas las ciencias militares [...] La opinión general decía que él conocía más sobre las familias, partidos y conexiones en Estados Unidos que ningún otro hombre en ellos; que sabía más sobre cada campaña, sitio, batalla y escaramuza sucedida en la guerra que cualquier oficial en nuestro ejército, o político en nuestro gabinete.

Adams desaprobó los resultados del viaje de Miranda por la nueva república, que para él fueron una fuente de consternación durante su presidencia, y años más tarde, en su vida privada ${ }^{15}$. Miranda iniciaría la primera ronda de negociaciones con Pitt al cabo de seis años de sus conversaciones con Henry Knox, entonces Secretario de Estado, y Alexander Hamilton, Secretario del Tesoro. Durante la segunda ronda de negociaciones en 1798, Miranda exploró la posibilidad de obtener ayuda adicional de sus amigos en Estados Unidos durante la presidencia de Adams. Fue allí, después de todo, que se cristalizó la idea de lograr la independencia de España;
Cruzando la frontera con Rousseau: Emilio y el Viaje por los Estados Unidos, 1783-1784 de Francisco de Miranda

JOSELYN M. ALMEIDA
Hamilton y me hubiesen dicho que estaban de acuerdo y me hubiesen aconsejado a participar en este ataque quijotesco contra un molino de viento, nunca lo hubiese hecho»). Adams, Works, (1856, vol. 10, p. 147). Miranda viajó por el norte de Europa en compañía de William Smith, el yerno de John Adams. Años más tarde, el nieto de Adams participó en la expedición de Miranda en 1806 sin su conocimiento. Véase también Adams (1856 vols. 10, pp. 135, 157). 
en 1792, Miranda escribe, «Pasé a examinar comparativamente los Estados Unidos de la América. Aquí fue que en el año de 1784 en la ciudad de Nueva York, se formó el proyecto actual de la Independencia y Libertad de todo el continente Hispano-Americano» (Miranda, 1982, p. 120).

El informe de Miranda al revolucionario Armand Gensonné ha originado interpretaciones que de alguna u otra manera reiteran la influencia estadounidense sobre el desarrollo del nacionalismo latinoamericano, un tema complejo que va más allá del alcance de este artículo. El método geográfico de Withers permite un análisis más matizado de las traslaciones textuales de la experiencia atlántica, las cuales sitúan a Miranda en relación a núcleos múltiples de conocimiento y nos permiten apreciar cómo transforma el viaje pedagógico roussoniano durante una época en que el viaje a América con fines epistemológicos se dedicaba principalmente a la exploración natural ${ }^{16}$. La predispocisión roussoniana al empirismo y a las ideas revolucionarias que Miranda trae a Estados Unidos se incuba primero en la Ilustración en España y América. En su afán empirista y preferencia por el conocimiento autóptico, Miranda también se acerca a los jesuitas criollos Francisco Clavijero, Juan de Velasco y Juan Ignacio Molina, quienes, como muestra Jorge Cañizares-Esguerra, corrigen las narraciones de viajeros Europeos que viajaban a prisa y frecuentemente se apoyaban en traducciones y opiniones de segunda mano al escribir sobre América (CañizaresEsguerra, 2006, p. 208). Clavijero, Velasco y Molina forjan, según Cañizares-Esguerra, «a patriotic epistemology» («una epistemología patriótica»), la cual define como «a discourse of the ancien régime that created and validated knowledge in the colonies [...] they articulated an original analysis of the epistemological limitations of the 'traveler' that foreshadowed many of our postcolonial insights» («un discurso del ancien régime que creó y validó el conocimento en las colonias [...] articularon un análisis de las limitaciones epistemológicas del 'viajero' [europeo] que anticipa nuestras interpretaciones postcoloniales» (2006, p. 206). Apoyados por la institucionalidad eclesiástica, incluso después de su expulsion en 1763, los jesuitas americanos sentaron las bases de su epistemología en lo autóctono. La adaptación que Miranda hace de Rousseau le permite ensayar una variante secularizada y peripatética de la epistemología patriótica, la cual transmuta la relación del sujeto colonial al estudio y el conocimiento. Si al comienzo de su jornada Miranda es un súbdito leal español, a medida que se identifica con lo americano (en el sentido hemisférico de esta palabra), también efectúa la transformación del esquema del viaje. Al concebir Estados Unidos como parte de su viaje de estudios, Miranda reclama para el sujeto americano el espacio discursivo del viajero y la función de productor de relaciones epistémicas y sociales mediante su diario, cartas y conversaciones. El análisis de estas relaciones revela cómo la ruptura de Miranda con España no es una conclusión inevitable, sino un proceso de alienación (Bushnell en Maher, 2006, p. 18). El cambio de su autoidentificación nacional manifiesta el desarollo epistémico, político y cívico que culmina en la última etapa de la pedagogía de Rousseau, y en la elección consciente y voluntaria de participar o rechazar el contrato social de su país natal "porque en virtud de un derecho que nadie puede revocar, al ser mayor de edad y dueño de si mismo, tiene el derecho de denunciar el contrato por el cual está ligado a la comunidad, dejando el país donde vive» (Rousseau, 1971, pp. 624-625).

Miranda siguió una ruta de sur a norte, llegando desde La Habana a New Bern, Carolina del Norte, el 1 de junio de 1783. Viajó por tierra y mar a través de Carolina del Sur, Pennsylvania, Nueva York, Connecticut, Massachusetts, Nuevo Hampshire y de regreso a Massachusetts, donde se embarcó para Inglaterra el 16 de diciembre de 1784. Sus investigaciones sobre las instituciones jurídicas, económicas, sociales y educativas de la nueva república evidencia la aplicación cívica del empirismo, que en Emilio es el criterio más importante para el viaje. Dondequiera que se encontraba, Miranda obtenía cifras sobre la población local y los impuestos, investigaba las leyes, las iglesias, la industria y el comercio, la prensa, la navegación y las milicias y armas. Hizo excursiones para examinar campos de batalla como Breed's Hill, donde ocurrió la batalla de Bunker Hill en Boston, West Point en Nueva York, $\mathrm{y}$ las fortificaciones que James Moncrieff, un destacado ingeniero británico, construyó
16

Alexander von Humboldt se convierte en el viajero prototípico a las Américas al comienzo del siglo XIX; veáse Mary Louise Pratt, Imperial Eyes: Travel Writing and Transculturation (1992) y Jorge Cañizares-Esguerra, Nature, Empire, and Nation: Explorations of the History of Science in the Iberian World (2006). En Estados Unidos, el viaje de Lewis y Clark estuvo ligado inextricablemente a la formación del país. Observan Peter Onuf y Jeffrey L. Hantman, «The expedition's mythic West provides a multicultural common ground for Americans of all backgrounds and persuasions, a place where white pioneers and Indians made love, not war, a place where the spirit of adventure remained unsullied by imperialistic impulses to kill, conquer and exploit» (2005, p. 2) («El oeste mítico de la expedición ofrece un terreno común multicultural para los estadounidenses de todos los orígenes y creencias, un lugar donde los pioneros blancos y los indios hacían el amor y no la guerra, un lugar donde el espíritu de aventura fue inmune a los impulsos imperialistas de matar, conquistar y explotar»).

Cruzando la frontera con Rousseau: Emilio y el Viaje por los Estados Unidos, 1783-1784 de Francisco de Mirand

JOSELYN M. ALMEIDA 


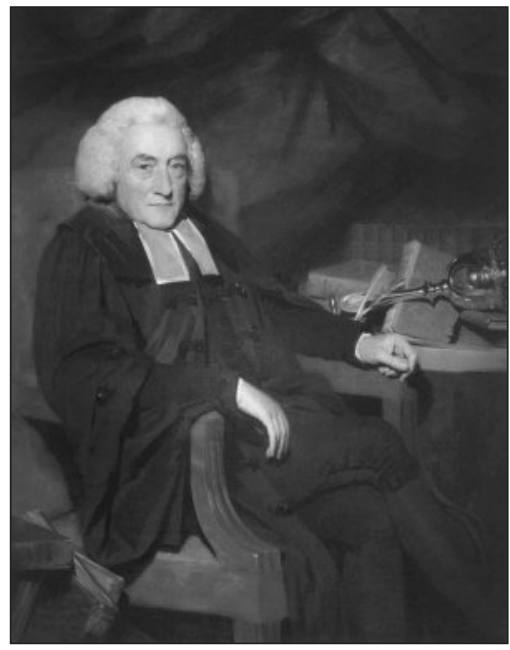

en Charleston. Fue recibido en los salones y los hogares de «founding fathers» (fundadores) como George Clinton, gobernador de Nueva York, Alexander Hamilton, Henry Knox y John Hancock, jueces como Adeanus Burke y académicos como los presidentes de Yale y Harvard, el Dr. Ezra Stiles y el Dr. Joseph Willard. Miranda también disfrutó de la sociedad de las mujeres republicanas, como narra Racine: «Miranda always liked women. He especially liked smart women and he chose women smartly» («a Miranda siempre le gustaron las mujeres. En William Robertson especial le gustaban las mujeres inteligentes y las eligió perspicazmente»; Racine, 2003, p. 47). Su relación con la heredera Susan Livingston de Nueva York fue suficientemente seria para causar un revuelo.

El deseo evidente que Miranda tenía de aprender todo sobre la nueva nación, y su conocimiento de la filosofía, las letras y los idiomas lo convirtieron en el huesped ideal, como indican las numerosas cartas de presentación que obtuvo. En Carolina del Sur, los ciudadanos David Ramsay y Salomon Hailing elogiaron sus modales, conversación, espíritu indagador, amor por la libertad y sentimientos liberales (Robertson, 1969, vol. 1, p. 45). William Duer, quien le dio una carta de presentación para Lord North después de conocer a Miranda en Nueva York, escribió: «He will be found a very Interesting Acquaintance, and I doubt not by Exchange of Useful Information in Matters of Science and Politics, endeavor to Compensate for any valuable communications which you and my friends may impart to him on the Constitution, Commerce, and Government of your country» («Se econtrará Ud. con un sujeto muy interesante, y no dudo que compensará cualquier información importante que le brinde sobre la constitución, el gobierno y el comercio de su país con información provechosa en materias de ciencia y política»). Henry Knox lo presentó a John Hancock como: «a Spanish Gentleman who [...] is desirous of seeing N. America and those Characters who have materially contributed to effect a revolution, which is contemplated through Europe with Astonishment» («un caballero español que [...] desea conocer Norteamérica y los personajes que han contribuído mate- rialmente a efectuar una revolución que se contempla por toda Europa con asombro») (citado en Robertson, 1969, vol. 1, p. 45).

El rango de Miranda como oficial en el ejército español también contribuyó al éxito de su auto-representación; desde su llegada en Carolina del Norte en junio de 1783 a enero de 1784, antes de llegar a Nueva York, se identificó como súbdito español y demostró su lealtad en Filadelfia. Mientras invernaba esta ciudad en 1783, Miranda se hospedó con Francisco Rendón, el cónsul español. Habla de «nuestro Rendón», anfitrión de una de las mejores fiestas de la temporarada, y destaca favorablemente los modales y la educación del diplomático. Una prueba inesperada de lealtad surge cuando Marbois, el asistente del cónsul francés, empieza una campaña negativa de relaciones públicas contra el ejército español, aludiendo específicamente a las operaciones contra los británicos en Jamaica. Marbois repitió el rumor que Miranda había ayudado al enemigo. Miranda observó: «Esta es su doctrina favorita y la máxima que con mayor ardor procuran inculcar en el espíritu de los americanos» (Miranda, 1978, vol. 3, p. 111). Cuando Rendón no supo qué responder a Marbois, Miranda sugirió una estrategia para protegerlo. Ambos intercambiarían cartas, una en la cual Miranda explicaría cómo los franceses estaban utilizando las acusaciones falsas contra él para socavar la alianza entre Estados Unidos y España, y a la cual Rendón contestaría confirmando la historia de Miranda (Miranda, 1978, vol. 3, p. 111). Aunque Miranda declaró que su motivo principal era ayudar a Rendón, también se beneficiaba de esta actuación epistolar; por infundadas que fuesen las acusaciones contra él, tendría que luchar por más de una década para eximir su nombre (Racine, 2003, p. 27). La protección mutua que Miranda y Rendón se ofrecieron dependía de la fe del cónsul español en la lealtad de Miranda. Al poco tiempo, Miranda le comunicó a Cagigal que desde La Habana se continuaban difundiendo rumores sobre su «deserción» del ejército. No podía negarlos abiertamente sin incriminar a Cagigal, quien lo había dejado en libertad, así que se marchó de Filadelfia, «por última prueba de mi fidelidad en cumplimiento con mi palabra, y manifestar más mi lealtad a V» (Miranda, 1978, vol. 3, p. 113).

Miranda corría el riesgo de ser capturado como desertor dada la alianza entre España 
y Estados Unidos, mas también se halló en medio de una corriente hispanófila al comienzo de la década de 1780. Aunque de magnitud más pequeña que los resurgimientos hispanistas en Alemania y Gran Bretaña al comienzo del siglo XIX, esta corriente sin duda facilitó el viaje de Miranda. El Quijote de Cervantes se conocía por medio de traducciones y era «an extraordinarily popular character among all classes of citizens in the English colonies» («un personaje muy popular para todas las clases de ciudadanos en las colonias inglesas» Cox, 1976, p. 104). Igualmente conocida era la History of America (1777) de William Robertson, la que influyó trabajos como el poema épico de Joel Barlow, The Vision of Columbus (1787), y la novela Reuben and Rachel (1798) de Susanna Rowson. Barlow, quien conocería a Miranda eventualmente en París, presenta un ángel que guía a Colón por un desfile de los lugares destacados de la historia estadounidense, «Fair [. . . Newport [...] / and Boston, [...] / Bright Charleston's roofs and sparkling spires, [...] Blest Baltimore», y le muestra figuras como William Penn y el Gobernador Winthrop. El crítico Ralph Bauer sostiene que «Joel Barlow was interested in [...] a hemispheric perspective (rather than imperial or nationalist) and a concern with the global meaning of America for human history at large» («a Barlow le interesaba una perspectiva hemisférica (en vez de una imperialista o nacionalista) y se preocupaba por el significado global de América para la historia de la humanidad»; Bauer, 1995, p. 207). Bauer demuestra que dicha «perspectiva hemisférica» también celebraba la resistencia indígena en poemas como La Araucana de Ercilla, que William Haley y Voltaire dieron a conocer en Francia e Inglaterra (Fulford, 2008, pp. 225-252). Hasta Thomas Jefferson aconsejó a su sobrino: «Bestow great attention to this [Spanish], and endeavor to acquire an accurate knowledge of it. Our future connection with Spain and Spanish America, will render that language a valuable acquisition. Then ancient history of that part of America, too, is written in that language» («Dedica tiempo al estudio y conocimiento del español. Nuestra conexión futura con España e Hispanoamérica hará de esta lengua una adquisición valiosa. La historia antigua de esa parte de América también está escrita en ella» (Jefferson, 2013, p. 32).
La imagen del viajero roussoniano en Emilio que Miranda cultivó desmintió los rumores contra él, aún después de que a Filadelfia y Nueva York llegara la noticia sobre un tal «Juan Miranda», fugitivo por cargos de contrabando. Para sus anfitriones, Miranda era el viajero ilustrado que Rousseau describía y no un renegado, hecho comprensible cuando se toma en cuenta la popularidad de Emilio en Estados Unidos. Los norteamericanos conocían bien la caracterización positiva que Rousseau le da al viajero español, a quien destaca porque «el español estudia en silencio el gobierno, las costumbres, y la policía, y él es el único de los cuatro [ingleses, franceses, alemanes, españoles] que saca del viaje observaciones útiles para su patria» (Rousseau, 1971, pp. 620-621). Observa Paul Merill Spurlin:

No book of Rousseau's appears to have been more advertised more often by American booksellers than the Emile ... It was available in English in Philadelphia as early as 1763, in Williamsburg in 1765, and in New York City in 1773. At one time or another, it could be purchased from Rhode Island to Georgia. The book was on the shelves of library societies. Harvard had it by 1774 . Patrons of certain circulating libraries had access to it toward the end of century [...] It heads a list of books in a pay-book which Alexander Hamilton kept in 1776 as a commander of a company of artillery [...] John Adams had in his library a French edition of Emile in four volumes, published in 1762 [...] Noah Webster and John Quincy were both familiar with the book. And so were Enos Hitchcock, New England Clergyman, Aaron Burr, Martha Laurens Ramsay, and others (Spurlin, 1969, p. 74).

Ningún libro de Rousseau se anunciaba en las librerías tanto como Emilio [...] Ya en 1763 se conseguía en Filadelfia en inglés, en Williamsburg en 1765, y en Nueva York en 1773; en una época, se podía comprar desde Rhode Island a Geogia. El libro se encontraba en las sociedades bibliotecarias. Harvard lo compra en 1774, y para el fin de siglo, los patronos de bibliotecas de circulación ya lo leían [...] Encabeza la lista de libros que Alexander Hamilton tenía en 1776 como comandante de artillería [...] John Adams tenía el Emilio en su biblioteca en cuatro tomos publicados en 1762 [...] Noah Webster y John Quincy también lo conocían, además de Enos Hitchcock, reverendo, Aaron Burr, Martha Laurens Ramsay y otros.

La presentación del tipo del viajero español en Emilio creó un contexto epistemológico y
Cruzando la frontera con Rousseau: Emilio y el Viaje por los Estados Unidos, 1783-1784 de Francisco de Miranda

JOSELYN M. ALMEIDA 


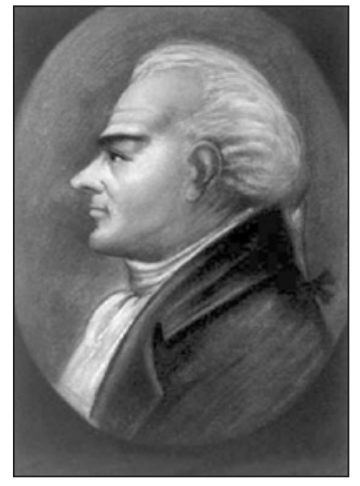

Miranda en 1806, por autor anónimo, EE.UU., 1806. Col. Alfredo Boulton
Cruzando la frontera con Rousseau: Emilio y el Viaje por los Estados Unidos, 1783-1784 de Francisco de Miranda

JOSELYN M. ALMEIDA literario para la recepción de Miranda, mas fue uno que él individualizó y reinscribió. Miranda además encarnaba el amor por la lectura y la curiosidad intelectual valorizados en la nueva república; la alfabetización y la prensa, como sostiene Benedict Anderson, contribuyeron a la formación nacional de Estados Unidos. El intercambio de libros, folletos, conversaciones y cartas iniciaron y desarrollaron relaciones sociales y políticas entre aquellos estadounidenses que tenían los medios para aprender.

Los libros y folletos que Miranda prestó, regaló, recibió y obtuvo hablan de su papel como productor y propagador del conocimiento y revelan la frontera abierta y transnacional de la Ilustración en Estados Unidos durante la década de 1780. John Vaughan, quien pasó a ser el presidente de la Sociedad Filosófica Americana de Filadelfia, escribió a Miranda que no podía imaginar su regreso a España, y le aconsejó que la tierra adecuada para que echara raíces era o Inglaterra o Estados Unidos. En Carolina del Norte, Miranda le prestó al marqués de Bretigny un volumen de poesía francesa; y de Robert Williams, un líder cuáquero, recibió An Apology for the True Christian Divinity (1678) por Robert Barclay y una traducción del mismo al español. Williams le dio la traducción ya que sentía que por fin había encontrado a la persona adecuada para difundir el trabajo en castellano, y le pidió que evaluara la calidad de la traducción. En Nueva York, Mary Walton, esposa del representante Lewis Morris, le envió a Miranda «mil gracias» por el préstamo de «la obra del señor Rousseau», que había leído con «mucha atención», y deseó «una memoria tan buena como la suya, para acordarme de todas las bellezas que se encuentran en este libro» (Miranda, 1978, vol. 3, p. 578). Una cierta señora Montgomery le devolvió dos de los tres libros que Miranda le había prestado, ya que se había «enamorado profundamente del tercer Helvecio y no puede concebir separarse de él», pero a cambio, ella le «deja una historia de la última guerra en América, escrita por un oficial que fue testigo de lo que escribió» (Miranda, 1978, vol. 3, p. 575).

Este entusiasmo por la lectura y el aprendizaje tenía sus límites, sin embargo. Las leyes que excluían a millares de afroamericanos de una cultura que por otra parte estaba dedicada a la difusión del conocimiento en la población, erguían prohibiciones contra la lectura y el alfabetismo tan severas como las inquisitoriales.
Miranda se vio ante este hecho cuando conoció a Phyllis Wheatley en Boston entre el mes de septiembre y el 5 de diciembre de 1784, el día que la escritora murió. Wheatley había logrado un reconocimiento internacional por su poesía, pero Miranda la encontró «[sufriendo] el mismo descuido que los talentos padecen en todas partes» y muriendo en la indigencia (Miranda, 1978, vol. 3, p. 306). A pesar de que Wheatley se había ganado su lugar en el mundo letrado que animó a la conciencia de la nueva república, Miranda atestiguó cómo el abandono de su talento reflejaba una actitud social que imponía su propia clase de silencio.

Si mediante los libros Miranda estableció relaciones políticas y sociales, las observaciones empíricas que hizo en campos de batalla y paisajes en su diario aumentaron su percepción de si mismo como americano en el sentido más amplio de la palabra. Esta auto-identificación se hizo evidente en Nueva York. Después de visitar a Fort Clinton en febrero, Miranda revisa la artillería y comenta sobre las instrucciones de Henry Knox para memorializar la batalla:

Han adoptado el estilo de poner una inscripción a todas las piezas que han tomado del enemigo [...] en que se lee el paraje, o sitio donde fue tomada [...] entre ellas se ven también cuatro pequeñas piezas de antigua construcción [...] que junto con dos morteros viejos de marina, componían todo el tren de artillería con el que comenzó el ejército americano a disputar la independencia de este continente (Miranda, 1978, vol. 3, p. 144).

Como lugares de memoria, los campos de batalla significan el telos de la nación que siempre se confirma en el presente del espectador, al mismo tiempo que invitan a la retrospección. Según Mary Favret, la escritura histórica a finales del siglo XVIII autoriza la apropiación del campo de batalla por el espectador, así como su reinterpretación personal de la historia. «Landscapes of historical significance came to offer greater play to imaginative remembrance than did the moral exemplars of classical history-writing; these sites [...] anchored an intense engagement with temporally distant experience». («Los paisajes con significado histórico ofrecían más amplitud para la memoria imaginativa que los ejemplos morales de la historia clásica; estos sitios [...] anclaron un encuentro intenso con experiencias alejadas en el tiempo» (Favret, 2010, p. 213)). 
En el caso de Miranda, la guerra de la independencia no estaba «alejada en el tiempo», por lo que su apropiación de la historia de Estados Unidos a través de este «encuentro» con el paisaje le impacta como participante. Para él, la «inscripción» memorial del campo de batalla indica un lugar específico que se registra como espacio nacional y a la vez marca un evento que tiene ramificaciones continentales, el «disputar la independencia de este continente». Su apropiación de la historia nacional de Estados Unidos reafirma su identidad como americano continental y marca la escisión respecto a su identificación con España, ya que Fort Clinton representa el lugar donde la filiación con Inglaterra (la «madre patria») se convirtió de destino inalterable en una elección. Dos meses más tarde, Miranda exterioriza su identificación con el paisaje como un americano en su descripción de Cohoes Falls en Albany. Escribe: «Las hierbas del campo exhalaban un olor tan aromático, los montes presentaban un aspecto tan feraz, los trigos y demás sementeras parecían tan bellos y frondosos y el terreno tan rico que se me antojaba estar en la isla de Puerto Rico, Cuba u otra parte de nuestro continente» (Miranda, 1978, vol. 3, p. 181). Las «hierbas del país», que Walt Whitman luego celebraría como una metáfora icónica de la poesía americana en Leaves of Grass (1855), ocasionan la revelación que el paisaje despierta en Miranda, en la cual desaparece la distancia entre «Nueva York, Puerto Rico, Cuba, o en otra parte de nuestro continente». El efecto de déjà vu lleva a Miranda a sentir en su persona la unidad del espacio americano, «nuestro continente», y al nombrar sus topónimos, a proyectarse sobre un imaginario hemisférico transnacional que integra a América, norte y sur.

\section{Conclusión: en la mesa con Emilio}

El periplo de Miranda con Rousseau en Viaje por Estados Unidos revela que el paso de la Ilustración al Romanticismo en el arco atlántico se desplegó como proceso cultural a través de geografías e idiomas diversos. No es el producto de un solo evento, local o texto, sino de la intersección de sucesos y relaciones textuales y sociales que repercuten en nuestro presente de manera asombrosa, como concluye Withers (2007, p. 242). Por ejemplo, en el conocido ensayo «The North American» (El norteamericano) Richard Rodríguez escribe:

Hispanics are changing the contour of the United States because we are north-south people. The United States has traditionally written its history east to west, has begun its story at Plymouth Rock and has ended up at Venice Beach, a country that has understood itself in one direction only. Suddenly, there are millions of Americans who see themselves along a north-south trajectory. That is a revolutionary regard (Rodríguez, 2003, p. 63).

Los hispanos están cambiando el contorno estadounidense porque estamos orientados hacia el norte y el sur. La historia de Estados Unidos se ha escrito tradicionalmente de este a oeste, comenzando en Plymouth Rock y terminando en Venice Beach, comprendiéndose el país en una dirección solamente. De repente hay millones de americanos que se ven a sí mismos en una trayectoria de norte a sur. Esta es una reflexión revolucionaria.

Miranda se convierte en uno de los primeros americanos que dirigen su viaje por esta «trayectoria de norte a sur», amplificándo así el fondo histórico de la «reflexión» que Rodríguez describe. Mas hay otro sentido en que la reflexión revolucionaria de Miranda todavía es palpable y se registra cuando vuelve sobre Emilio al final de su viaje. En octubre de 1784, un mes antes de partir a Londres, cenó con la familia Tracy, dueños de una compañía naviera. Miranda escribe: «Tuvimos nuestra buena: comida en el estilo Americano, con algo de la doctrina rousseauiana en la conversación», y añade entre paréntesis: «El Emilio compareció en la mesa» (1980, vol. 3, p. 327). Nunca se sabrá con certeza si la referencia enigmática indica que los Tracy le mostraron una copia del libro o lo discutieron en conexión al viaje de Miranda, posibilidades factibles dada la popularidad extraordinaria de Emilio en aquella época. Queda claro, sin embargo, que al igual que el protagonista de Rousseau, Miranda desarrolló una epistemología del viaje que germinó su realización política, y suscitó su transformación de sujeto colonial a uno que libró una lucha incansable por un espacio que le permitiera vivir su verdad. Las travesías atlánticas que hizo a lo largo de su vida nos recuerdan que «La libertad no está en ninguna forma de gobierno, pero está en el pecho del hombre libre, y la lleva consigo a todas partes» (Rousseau, 1971, p. 649).
Cruzando la frontera con Rousseau: Emilio y el Viaje por los Estados Unidos, 1783-1784 de Francisco de Miranda

JOSELYN M. ALMEIDA 


\section{Bibliografía}

Adams, John (1856), The Works of John Adams, Second President of the United States: with a Life of the Author, Notes, and Illustrations by his Grandson Charles Francis Adams. 10 vols, Boston, Little Brown and Co., vol. 10. Disponible en [The Online Library of Liberty, 2013].

Almeida, Joselyn M. (2011), Reimagining the Transatlantic, 1780-1890, Surrey, Ashgate.

Almeida, Joselyn M. (2013), «Romancing Post-Napoleonic Britain: The Metrical Fabulation of Simón Bolívar», en Urban Identity and the Atlantic Public Sphere, ed. Elizabeth Fay y Leonard von Morzé, New York, Palgrave, pp. 101-122.

Álvarez Barrientos, Joaquín, François Lopez, e Inmaculada Urzainqui (1995), La república de las letras en la España del Siglo XVIII, Madrid, Consejo Superior de Investigaciones Científicas.

Anderson, Benedict (1991), Imagined Communities: Reflections on the Origin and Spread of Nationalism, London,Verso.

Barlow, Joel (1787), The Vision of Columbus: a poem ... By Joel Barlow, Esquire, London: Disponible en: [Eighteenth Century Collections Online. Gale. University of Massachusetts, Amherst](Consultado 01/01/2011).

Bauer, Ralph (1995), «Colonial Discourse and Early American Literary History: Ercilla, the Inca Garcilaso, and Joel Barlow's Conception of a New World Epic», en Early American Literature, n. 30, 1995, pp. 203-232.

Blanco White, Joseph (1812), «Sobre la política práctica», El Español, 30 octubre 1812, pp. 401-432.

Bethencourt, Francisco (2009), The Inquisition: a global history, 1478-1834, traducc. Jean Birrell, Cambridge, Cambridge UP.

Bushnell, David (2006), "The Venezuelan Precursor», en John Maher (ed.) (2006), Francisco de Miranda: Exile and Enlightenment, London, Institute for the Study of the Americas, pp. 7-21.

Cañizares-Esguerra, Jorge (2006), Nature, Empire, and Nation: Explorations of the History of Science in the Iberian World, Stanford, Stanford UP.

Cruzando la frontera con Rousseau: Emilio y el Viaje por Francisco de Miranda

JOSELYN M. ALMEIDA Cañizares-Esguerra, Jorge (2001), How to Write a History of the New World, Stanford, Stanford UP.
Cortes, Jacqueline (1981), «Les idées de Miranda sur la vie sociale.» Cabiers $d u$ monde hispanique et luso-brésilien 37, pp. 291-292.

Cox, Meritt R (1976), «Spain and the Founding Fathers», en The Modern Language Journal 60.3, pp. 101-109.

Cutmore, Jonathan, ed. (2013) The Quarterly Review Archive. Romantic Circles. Ed. Neil Fraistat, Steven E. Jones, y Laura Mandell, University of Maryland (Consultado 12/07/2012).

Deforneaux, Marcelin (1973 [1963]), La Inquisición y censura de libros en la España del Siglo XVIII, traducido por J. Ignacio Tellechea Idigoras, Salamanca, Taurus Ediciones [Publicado originalmente bajo el título L'Inquisition espagnole et les livres français an XVIIIe siècle, Paris, Presses Universitaires de France].

Deforneaux, Marcelin (1959), Pablo de Olavide, ou l'Afrancesado, Paris, Presses Universitáires de France.

Domínguez Ortiz, Antonio (2005), Carlos III y la España de la Ilustración, Madrid, Alianza Editorial.

Esdaile, Charles (2008), Napoleon's Wars: an International History, 1803-1815, New York, Penguin Books.

Favret, Mary (2010), War at a distance: Romanticism and the making of modern wartime, Princeton, Princeton UP.

Fisher, Lillian Esther (1971), Champion of Reform: Manuel Abad y Queipo, New York, Russell and Russell.

Fulford, Tim (2008), «British Romantics and Native Americans: the Araucanians of Chile» en Studies in Romanticism, n. 47.2, pp. 225-252.

García, Láutico (1961), Francisco de Miranda y el Antiguo Régimen Español, Caracas, Academia Nacional de La Historia.

García Rosell, César (1970), Miranda y los ex-jesuitas desterrados, Caracas, Ediciones del Instituto de Estudios Históricos Mirandino.

Heinowitz, Rebecca Cole (2010), Spanish America and British Romanticism: rewriting conquest, 1777-1826, Edinburgh, Edinburgh UP, pp. 158-182.

Hernández González, Manuel (2006), Francisco de Miranda y su ruptura con España, Venezuela, Academia Nacional de Historia.
Herr, Richard (1969), The Eighteenth Century Revolution in Spain, Princeton, Princeton UP. 
[Inquisición] (2012), Archivo Histórico Nacional, Madrid.

Jaksic, Iván (2001), Andrés Bello: scholarship and nation building in Nineteenth Century Latin America, Cambridge, Cambridge UP.

Jefferson, Thomas (2013), The Best Letters of Thomas Jefferson, ed. J.G. de Roulhac Hamilton, Boston, Houghton Mifflin Company. Disponible en [Hathi Trust Digital Library. Committee on Institutional Cooperation](Consultado 14/07/2012).

Lynch, John (2006), Simón Bolivar: A Life, New Haven, Yale UP.

Maher, John (ed.) (2006), Francisco de Miranda: Exile and Enlightenment, London, Institute for the Study of the Americas.

Miranda, Francisco de (1982), América espera, ed. JL Salcedo Bastardo, Caracas, Biblioteca Ayacucho.

Miranda, Francisco de (1929-1950), Archivo del General Miranda, ed. Vicente Dávila, Caracas, Editorial Sur-Americana, 24 vols.

Miranda, Francisco de (1978), Colombeia, ed. JL Salcedo-Bastardo y Josefina Rodríguez de Alonso, Caracas, Ediciones de la República, 18 vols.

Miranda, Francisco de (1929), The Diary of Francisco de Miranda: Tour of the United States, 1783-1784, ed. William Spence Robertson, New York, The Hispanic Society of America.

Martineau, Harriet (1858), History of the Peace: Pictorial History of England During the Thirty Years Peace 1816-1846, London, W. and R. Chambers.

Pérez, Joseph (2005), The Spanish Inquisition: a History, New Haven, Yale UP.

Perojo Arronte, Maria Eugenia (2010), «Spanish Romanticism and the Struggle for Legitimation: Translation, Censorship, and the Development of the Movement.» en Denise Merkle, Carol O’ Sullivan, Luc van Doorslaer, and Michaela Wolf (eds.) The Power of the Pen: Translation and Censorship in Nineteenth Century Europe, Berlin, LIT Verlag.

Pons, André (2006), Blanco White y América. Oviedo, Instituto Feijoo de Estudios del Siglo XVIII.

Pratt, Mary Louise (1992), Imperial Eyes: Travel Writing and Transculturation, London, Routledge.
Racine, Karen (2003), Francisco de Miranda: A Transatlantic Life in the Age of Revolution, Wilmington, SR Books.

Robertson, William Spence (1929), «Introduction» en Francisco de Miranda, The Diary of Francisco de Miranda: Tour of the United States, 1783-1784, New York, The Hispanic Society of America, pp. IIIXXXVI.

Robertson, William Spence (1969), The Life of Miranda, New York, Cooper Square Publishers, 2 vols.

Rodríguez Aledón, Germán (2012), «Rousseau en la revolución liberal española: $\mathrm{La}$ primera edición en España de El Contrato Social» Cuadernos de Ilustración y Romanticismo: Revista digital del Grupo de Estudios del Siglo XVIII, Universidad de Cádiz, n. 18 (2012), pp. 212-230.

Rodriguez, Richard (2003), «The North American.» Public Discourse in America: Conversation and Community in the Twenty-First Century, ed. Judith Rodin, Philadelphia, University of Pennsylvania Press, pp. 60-70.

Rousseau, Jean Jacques (1971), Emilio, o la educación, Trans. Ángeles Cardona de Gibert, Barcelona, Bruguera.

Rousseau, Jean Jacques (2013), Emile, ou, De l'éducation. ARTFL-FRANTEXT. Department of Romance Languages and Literatures, University of Chicago, 2013. (Consultado 17 Feb. 2013)

Rosenblatt, Helen (2007), Rousseau and Geneva: from The First Discourse to the Social Contract, Cambridge, Cambridge UP.

Rowson, Susanna (2009), Reuben and Rachel, ed. Joseph Bartolomeo, Ontario, Broadview Press.

Saglia, Diego (2000), Poetic Castles in Spain: British Romanticism and Figurations of Iberia, Amsterdam, Rodopi.

Onuf, Peter y Hantman, Jeffrey L (2005), Across the continent: Jefferson, Lewis and Clark, and the Making of America, Virginia, Universidad de Virginia.

Spell, J. R. (1935), «Rousseau in Spanish America», en The Hispanic American Historical Review, 15. 2, pp. 260-267.

Spell, J. R (1969 [1938]), Roussean in the Spanish World Before 1833: a Study in Franco-Spanish Literary Relations, [2 ${ }^{\text {nd }}$. ed. Austin, University of Texas Press, 1938], New York, Octagon Books.
Cruzando la frontera con Rousseau: Emilio y el Viaje por los Estados Unidos, 1783-1784 de Francisco de Miranda

JOSELYN M. ALMEIDA 
Spurlin, Paul Merill (1969), Roussean in America, Alabama, Univ. of Alabama.

Thorning, Joseph (1952), Miranda: World Citizen, Tallahasee, Univ. of Florida P.

Warner, James H (1944), «Emile in Eighteenth-Century England.» PMLA 59.3, 1944, pp. 773-791.

Wellesley, Richard Colley y William, Jacob (1987), "Review of Des Colonies et de l'Amérique and Des trois derniers Mois d'Amérique by De Pradt; Outline of the
Revolution in Spanish America», The Quarterly Review, 17.2 (1817), pp. 530562.

Withers, Charles (2007), Placing the Enlightenment: Thinking Geographically About the Age of Reason, Chicago, University of Chicago Press.

Fecha de recepción: 14/02/2013

Fecha de aceptación: 29/07/2013 